\title{
Effect of metformin use on the risk and prognosis of endometrial cancer: a systematic review and meta-analysis
}

Danxia Chu, Jie Wu, Kaili Wang, Mengling Zhao, Chunfang Wang, Liuxia Li and Ruixia Guo*

\begin{abstract}
Background: Previous studies have suggested that metformin may be useful for preventing and treating endometrial cancer (EC), while the results have been inconsistent. This systematic review and meta-analysis aimed to investigate the association between metformin use and risk and prognosis of patients with EC.

Methods: PubMed, Embase, and the Cochrane Library databases were searched for observational studies evaluating the effect of metformin on EC prevention or treatment. The odds ratio (OR) was used for analyzing risks, and the hazard ratio (HR) was used for analyzing survival outcomes. A random-effects model was used for data analysis.

Results: Seven studies reported data on EC risk. The pooled results suggested that metformin was not significantly associated with a lower risk of EC [OR $=1.05,95 \%$ confidence interval $(\mathrm{Cl}) 0.82-1.35, \mathrm{P}=0.70]$. For patients with diabetes, metformin showed no advantage in reducing the $\mathrm{EC}$ risk compared with other interventions $(\mathrm{OR}=0.99$, $95 \% \mathrm{Cl} 0.78-1.26, \mathrm{P}=0.95)$. Further, seven studies were included for survival analysis. The pooled data showed that metformin could significantly improve the overall survival of patients with $E C(H R=0.61,95 \% \mathrm{Cl} 0.48-0.77, P<0.05)$ and reduce the risk of $\mathrm{EC}$ recurrence $(\mathrm{OR}=0.50,95 \% \mathrm{Cl} 0.28-0.92, P<0.05)$ Finally, we noted metformin was associated with significantly improving the overall survival of EC patients among diabetes $(\mathrm{HR}=0.47 ; 95 \% \mathrm{Cl} 0.33-0$. 67, $P<0.05)$
\end{abstract}

Conclusions: This meta-analysis did not prove that metformin was beneficial for preventing EC. However, metformin could prolong the overall survival of patients with EC and reduce their risk of cancer relapse.

Keywords: Endometrial cancer, Metformin, Risk, Prognosis, Meta-analysis

\section{Background}

Endometrial cancer $(\mathrm{EC})$, a tumor originating from the endometrium, is a major cause of morbidity and mortality in women. Hyperplastic endometrium may be a result of exposure to unopposed estrogen, leading to the progression of cancer. It is the most common malignancy of the female genital tract in the United States, with approximately 54,870 new cases and 10,170 related deaths in 2015 [1]. The incidence of EC is lower in developing countries compared with developed countries. However, EC was associated with higher cancer mortality and poor prognosis in developing countries [1-3]. Further, despite

\footnotetext{
* Correspondence: grxcdxzzu@163.com

Department of Gynecology, The First Affiliated Hospital of Zhengzhou

University, NO.1, JianShe East Road, Zhengzhou 450052, Henan, China
}

advances in the treatment of EC, the prognosis for stages III-IV EC remains poor [4].

Various adjuvant medications have been suggested for preventing and treating EC, including aromatase inhibitors [5], aspirin [6], statins [7], hormone therapy [8], and metformin $[9,10]$. Metformin has several advantages in addition to its anticancer activity. First, it is a first-line pharmacologic treatment for patients with type 2 diabetes mellitus [11]. Second, in addition to metformin use for diabetes, it is also safely prescribed for various nondiabetic conditions, including polycystic ovarian syndrome [12], primary prevention of type 2 diabetes mellitus and cardiovascular diseases [13, 14], and obesity control [15]. Finally, metformin is readily available worldwide at low cost.

(c) The Author(s). 2018 Open Access This article is distributed under the terms of the Creative Commons Attribution 4.0 International License (http://creativecommons.org/licenses/by/4.0/), which permits unrestricted use, distribution, and reproduction in any medium, provided you give appropriate credit to the original author(s) and the source, provide a link to the Creative Commons license, and indicate if changes were made. The Creative Commons Public Domain Dedication waiver (http://creativecommons.org/publicdomain/zero/1.0/) applies to the data made available in this article, unless otherwise stated.
} 
Type 2 diabetes mellitus is a well-established risk factor for EC $[16,17]$. Insulin resistance has been suggested to be one of the critical biological processes that contribute to EC $[18,19]$. Approximately $30 \%$ of patients with EC have type 2 diabetes mellitus, and up to $36 \%$ have undiagnosed insulin resistance [20]. Metformin use could reduce the risk of type 2 diabetes mellitus and delay its progression. It reduces insulin resistance by increasing insulin receptor tyrosine kinase activity, enhancing glycogen synthesis, and promoting the recruitment and increasing the activity of glucose transporter type 4 [21]. Moreover, it affects endometrial maturation, proliferation, and implantation process [22-24]. Finally, the risk of EC is increased in women who have higher endogenous estrogen levels [25], and metformin has been reported to hinder estrogen-mediated endometrial proliferation [26].

Several studies have reported that metformin is a promising intervention for preventing and treating EC. However, these studies had conflicting results, and no relevant meta-analyses have been conducted. Therefore, this systematic review and meta-analysis was performed to evaluate the effectiveness of metformin for the risk and survival outcomes in patients with EC.

\section{Methods}

\section{Search strategy}

This meta-analysis was performed according to the Preferred Reporting Items for Systematic Reviews and Meta-Analysis guidelines (Additional file 1) [27]. PubMed, Embase, and the Cochrane Library databases were searched for eligible studies between 1980 and July 2016. The following key words and medical terms were used for the literature search: (metformin OR glucophage OR dimethylbiguanide OR dimethylguanylguanidine) AND (endometrial cancer OR endometrial carcinoma OR endometrial hyperplasia OR endometrial proliferation OR endometrial thickness). The language was limited to English. Manual searching was also conducted on the reference lists of included studies and reviews for potentially relevant studies.

\section{Inclusion criteria}

Articles were included in the study if they met the following criteria: (1) used metformin for preventing or treating EC; (2) evaluated the incidence of EC or survival outcomes; the survival endpoints were overall survival (OS), recurrence-free survival (RFS)/disease-free survival, or the recurrence rate; (3) directly reported the effect estimates of odds ratio (OR), hazard ratio (HR), or relative risk (RR); (4) indirectly reported data allowing for the calculation of these effect estimates; and (5) the study with observational design. Abstracts, unpublished data, and studies not published in English were excluded.

\section{Data collection and quality assessment}

Two reviewers independently examined the included studies for eligibility and extracted the data. Any disagreement was resolved by consensus. The following information from each included study was extracted into standardized tables: author, publication year, region, study design, sample size, age, patient characteristics, EC incidence, percentage of metformin use in DM patients, proportion of patients with diabetes, reported effect estimates, degree of adjustment, and study period. When multiple studies for the same cohort were found, the most comprehensive or most recent data were used. The same reviewers independently evaluated the risk of bias using the Newcastle-Ottawa Scale [28]. This scale assigned 0-9 points based on three items: selection, comparability, and outcome assessment. Studies with $0-3,4-6$, and 7-9 points were classified as low-, medium-, and high-quality studies, respectively.

\section{Statistical analysis}

ORs and their associated 95\% confidence intervals (CIs) were used as the effect measures for the outcome of EC risk. HRs and associated 95\% CIs were used as the effect measures for the survival outcomes. Adjusted ORs or HRs were preferred for the analyses. However, if the adjusted effect estimates were not directly presented, they were calculated from the crude data available. HR was considered to be equivalent to $R R$ in cohort studies. Given the low incidence of EC, HRs could be assumed to be accurate estimates of ORs. When a study presented only KaplanMeier curves, HRs and 95\% CIs were calculated based on published methods [29]. A fixed-effects model was used for the data combination of different subgroups in a single study. The result from a random-effects meta-analysis is more conservative than that from a fixed-effects model. Thus, the between-study results were pooled using the random-effects model proposed by DerSimonian and Laird [30]. The heterogeneity between studies was evaluated with $\mathrm{Q}$ and $I^{2}$ statistics [31]. $I^{2}$ values between $0 \%$ and $25 \%$ were designated as a low level, values more than $25 \%$ as a moderate level, and values more than $75 \%$ as a high level of heterogeneity. The heterogeneity was explored by subgroup, meta-regression, and sensitivity analyses. The publication bias was examined visually by the symmetry of funnel plots and statistically by Egger's or Begg's tests [32, 33]. All statistical analyses were performed using Stata software (version 12.0, Stata Corporation, TX, USA). All statistical tests were two sided. A $P$ value less than 0.05 was considered statistically significant.

\section{Results}

Study selection

The PRISMA flow diagram of the identification and selection of studies is shown in Fig. 1. From a total of 246 


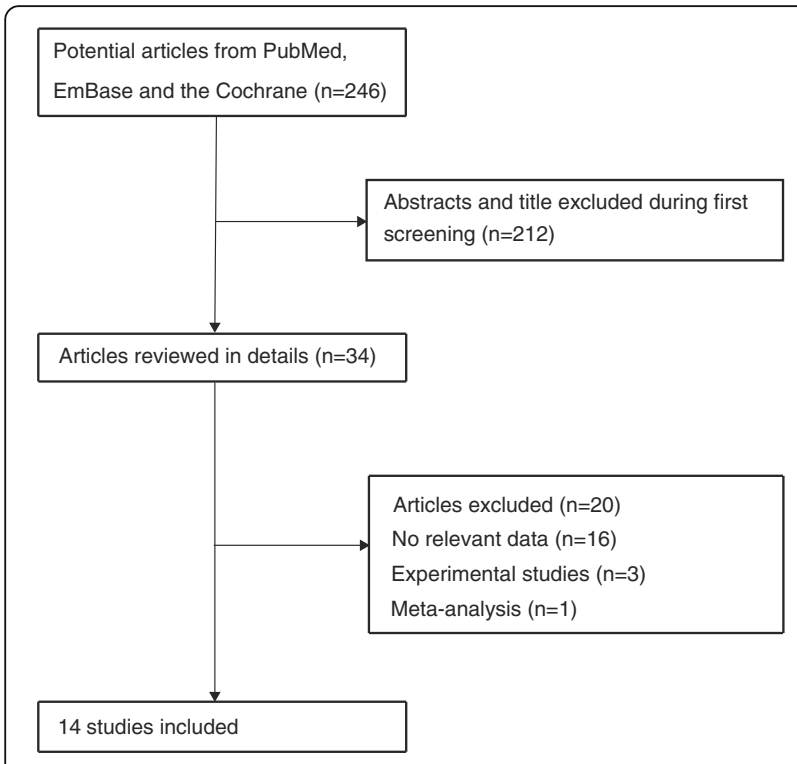

Fig. 1 Flow diagram of the study selection process

publications (141 from PubMed, 97 from Embase, and 8 from the Cochrane Library), duplicates were removed and irrelevant studies or those without sufficient data discarded. Finally, 13 studies were pooled in the metaanalysis, including 7 studies on the risk of EC [34-40] and 7 studies on the survival outcomes of EC [9, 10, 41-45].

\section{Study characteristics and quality evaluation}

The characteristics of the seven studies on EC risk are shown in Table 1, including two case-control studies $[34,39]$, four retrospective studies [36-38, 40], and one prospective study [35]. These studies were all published between 2013 and 2017. Two studies were conducted in the United States [35-37], three in Europe [34, 39, 40], and one in China [38]. The sample size ranged from 7861 to $4,478,921$. Six studies reported the adjusted ORs [34-36, 38-40], and one study reported only the crude data [37]. The incidence of EC ranged from $0.1 \%$ to 14 . $3 \%$ of included studies. The features of the studies on EC prognosis are shown in Table 2. All of the studies were retrospectively designed, including five studies in the United States $[9,10,41,43,44]$ and two studies in Europe [42, 45]. The sample size ranged from 107 to 1303. Except for a study that included only cases of advanced EC [44], most of the studies primarily included patients with early-stage EC (70\%-82\%). The proportion of patients with diabetes ranged from $17 \%$ to $100 \%$. Hall et al. only presented crude data on recurrence rates [10], but the other studies reported adjusted data. The quality appraisal of the included studies is summarized in Additional file 2. All studies were of high quality, with a score of 8-9.

\section{Metformin and the risk of EC}

Seven studies were eligible for the meta-analysis. Becker et al. analyzed the risk based on different metformin prescriptions $(1-24$ and $\geq 25)$ [34]. The data were first pooled in a fixed-effects model. Six studies presented the adjusted ORs. The pooled data showed that metformin use was not associated with the risk of $\mathrm{EC}(\mathrm{OR}=1$. 05, 95\% CI 0.82-1.35, $P=0.70$ ) (Fig. 2). High heterogeneity was shown among the studies $\left(I^{2}=90.9 \%, P<0.05\right)$. In the sensitivity analysis, the exclusion of any single study did not markedly alter the overall effect size, and in stratified analyses, the overall effect was not significantly changed for the subgroups by geographic region (USA, Europe, or Asia) and study design (case-control, prospective, or retrospective). However, no heterogeneity was detected in two European case-control studies $\left(I^{2}=0\right)$. In the meta-regression analysis, the sample size could not explain the source of heterogeneity $(P>0.05)$. The funnel plot appeared to be symmetrical (Fig. 3a). Notably, a significant publication bias was revealed by the Egger's test $(P<0.05)$, but not by the Begg's test $(P=1.00)$. The conclusions were not changed after adjustment for publication bias by using the trim and fill method [46].

The association between metformin and EC risk was further investigated in patients with diabetes. Franchi et al., Tseng et al. and Arima et al. included only patients with type 2 diabetes mellitus [37-40]. Three other studies reported data for subpopulations with type 2 diabetes mellitus [34-36]. The pooled data showed that patients with diabetes using metformin did not have a substantially lower risk of EC compared with those receiving other interventions $(\mathrm{OR}=0.99,95 \% \mathrm{CI} 0.78-1.26, P=0$. 95) (Fig. 4). However, high heterogeneity was detected $\left(I^{2}=89.9 \%, P<0.05\right)$.

\section{Metformin and OS of EC}

Six retrospective studies were included in this analysis. Ezewuiro et al. and Al Hilli et al. separately reported data for patients with diabetes not using metformin and those without diabetes $[43,44]$. The data from the subgroups within a single study were first pooled using a fixed-effects model. The pooled data showed that metformin use in patients with EC was significantly associated with longer OS compared with patients with EC not using metformin (HR $=0.61,95 \%$ CI $0.48-0.77, P<$ $0.05)$ (Fig. 5). Low heterogeneity was identified, which was not significant $\left(I^{2}=8.1 \%, P=0.36\right)$. No single study markedly changed the overall effect in the sensitivity analysis. In the subgroup analysis, the results were not significant for two European studies (HR $=0.74,95 \% \mathrm{CI}$ 0.37-1.49, $P=0.41$ ), but were significant for the four studies conducted in the USA (HR $=0.59$, 95\% CI $0.45-$ $0.76, P<0.05)$. When stratified by the percentage of 


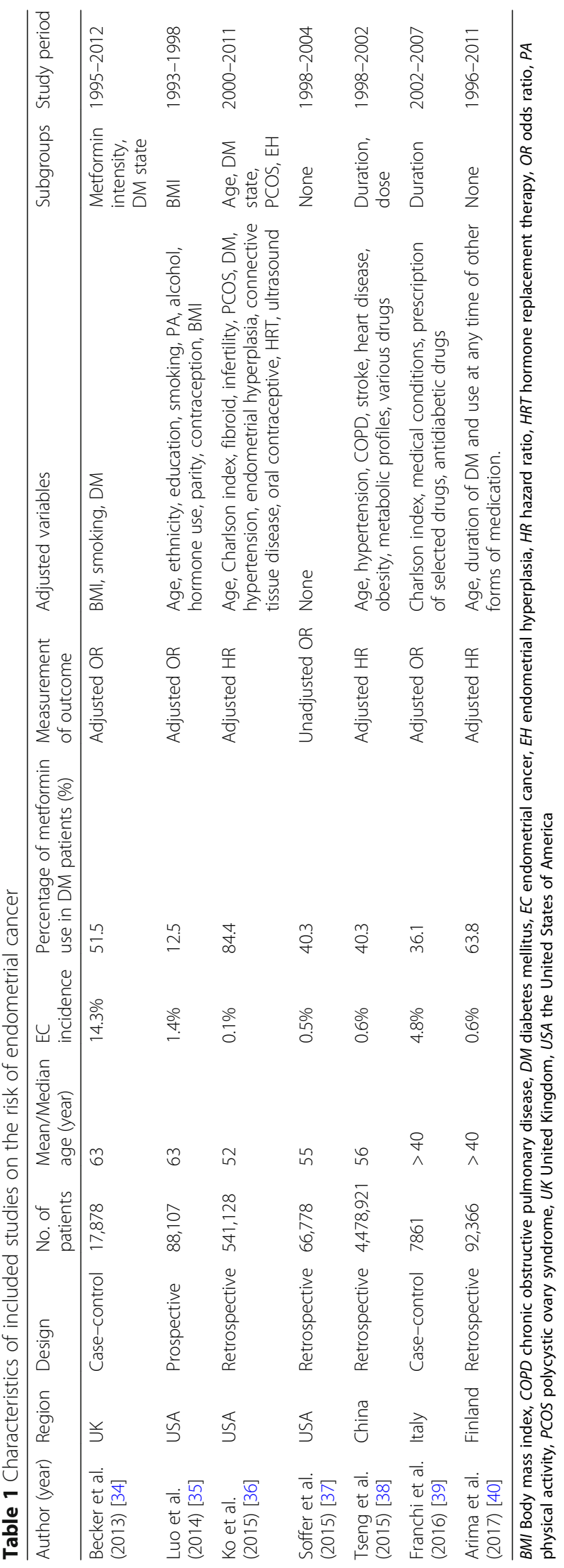


Chu et al. BMC Cancer (2018) 18:438

Page 5 of 11

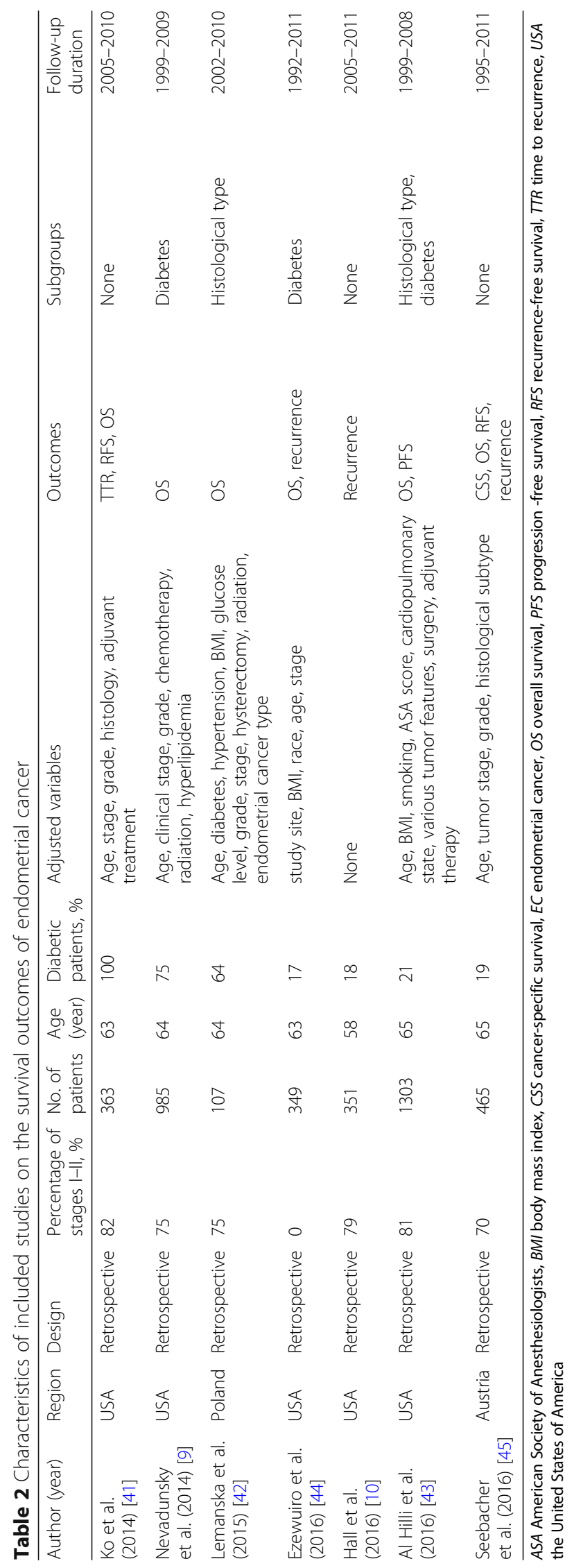




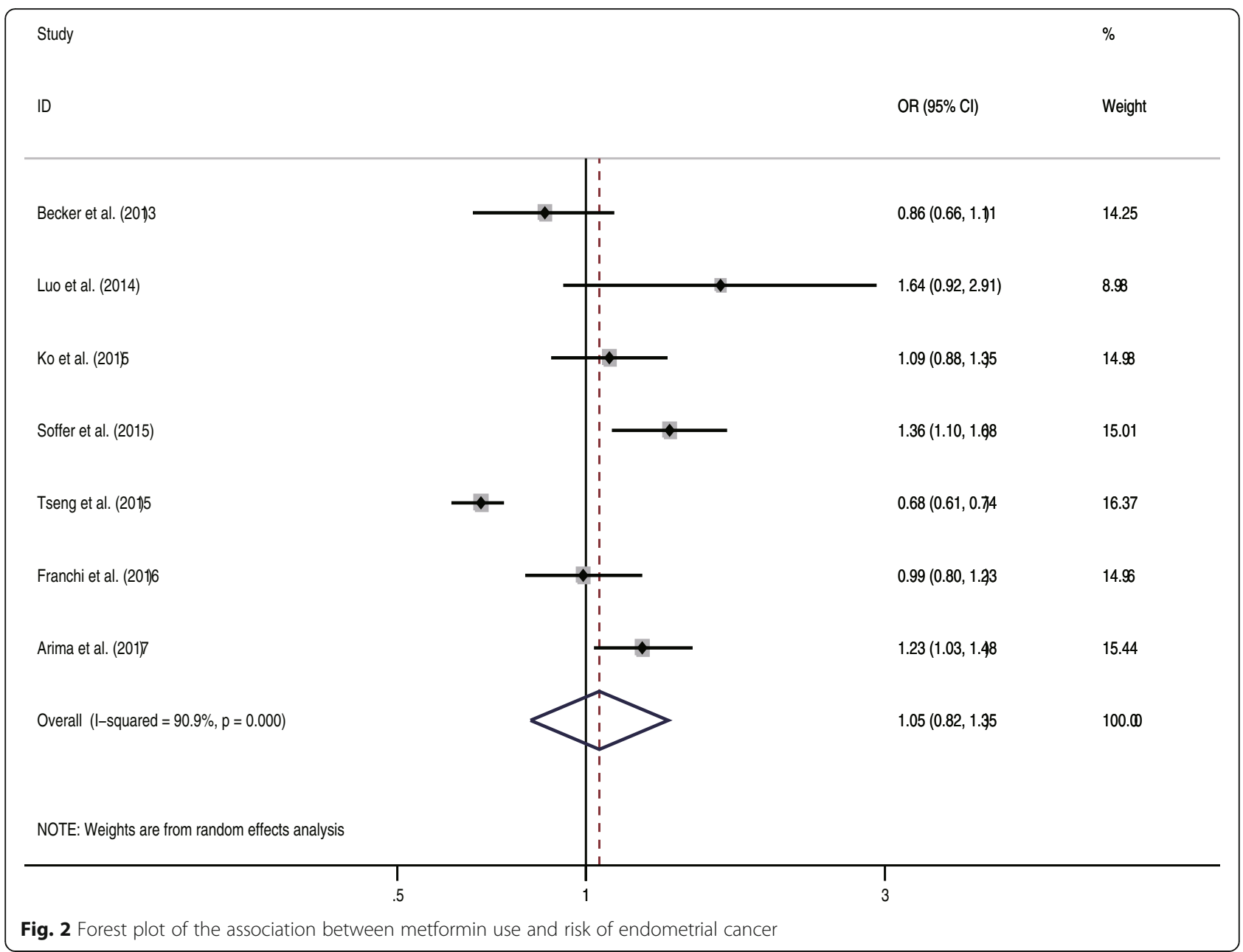
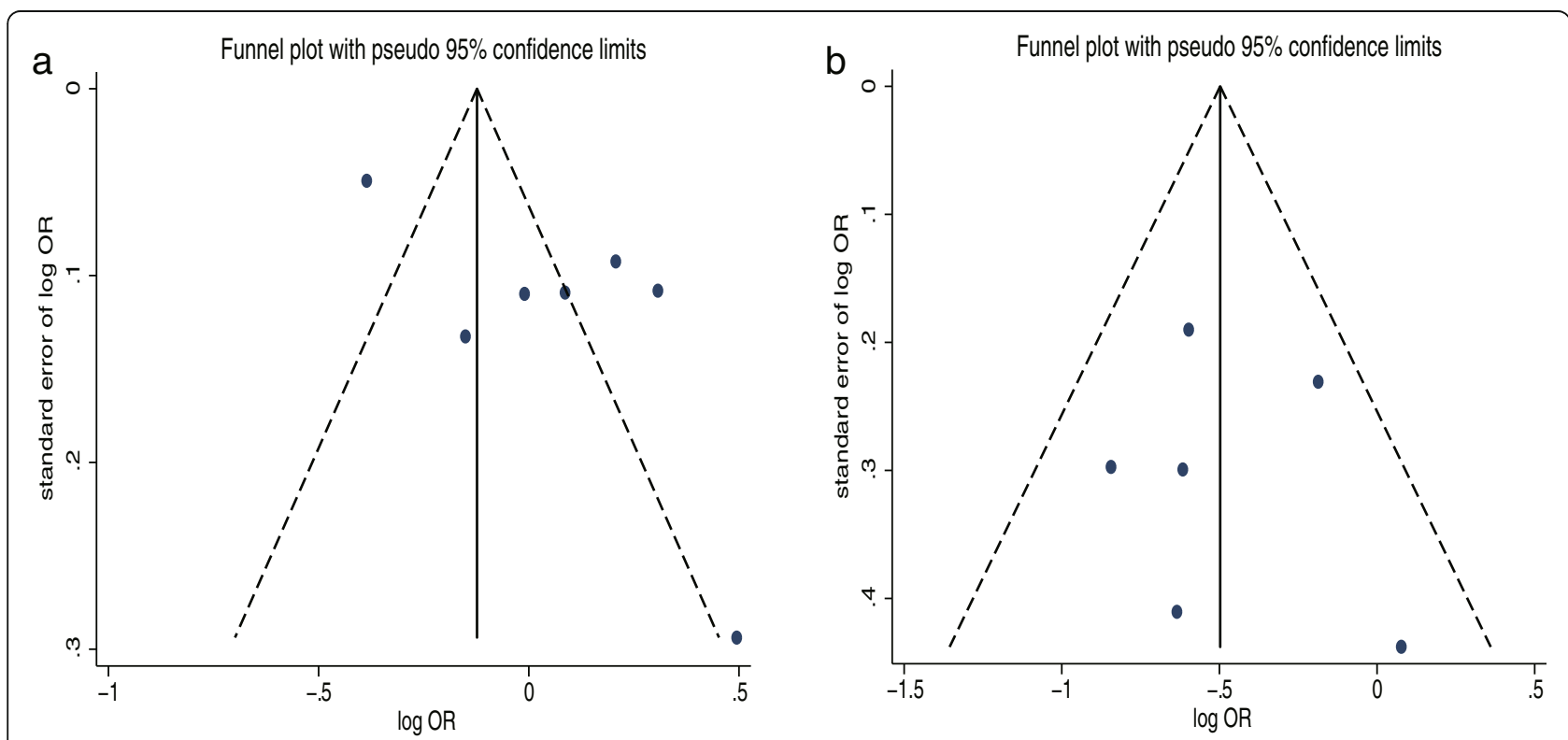

Fig. 3 Funnel plot of the included studies: a Studies presenting the association between metformin use and risk of endometrial cancer (EC). $\mathbf{b}$ Studies presenting an adjusted hazard ratio for the association between metformin use and overall survival of EC 


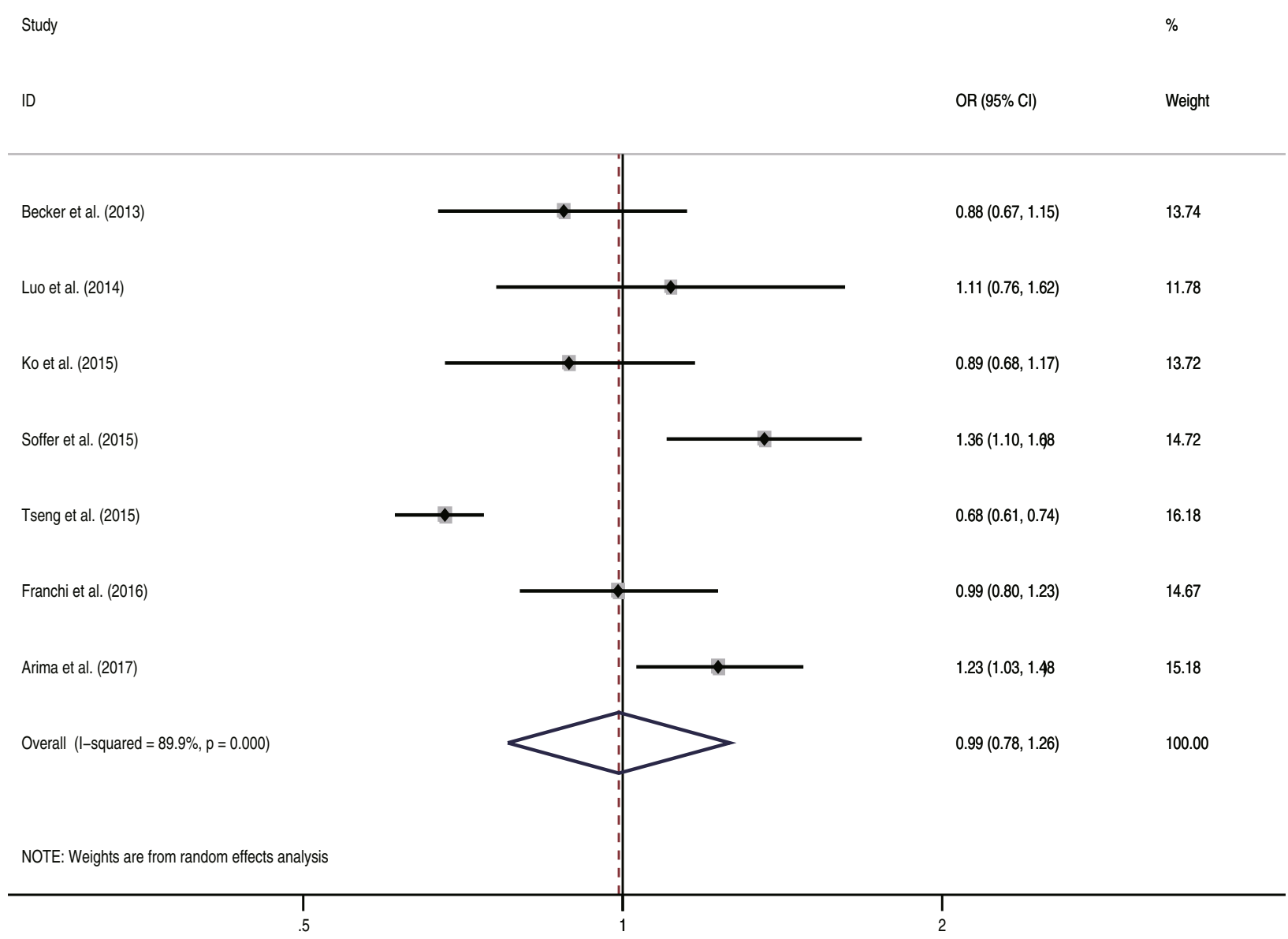

Fig. 4 Forest plot of the association between metformin use and risk of endometrial cancer among patients with diabetes

patients with type 2 diabetes mellitus (<50\% vs $\geq 50 \%)$, the overall effect had no substantial change. The metaregression analysis revealed no significant role of sample size $(P=0.81)$, proportion of stages I-II patients $(P=0$. 88 ), or percentage of patients with type 2 diabetes mellitus $(P=0.84)$ to account for the heterogeneity. The funnel plot seemed to be symmetrical (Fig. 3b). No significant publication bias was shown by the Egger's test $(P=0.78)$ or the Begg's test $(P=0.45)$.

The efficacy of metformin was further investigated among patients with EC having diabetes. Three studies reported relevant data. Metformin use was significantly associated with improved OS compared with other antidiabetic regimens $(\mathrm{OR}=0.47,95 \% \mathrm{CI} 0.33-0.67, P<0.05)$ (Fig. 6). No heterogeneity was detected $\left(I^{2}=0 \%, P=0.69\right)$.

\section{Metformin and recurrence of EC}

Three studies reported data on the recurrence of EC [10, $44,45]$. The pooled results suggested that metformin use in patients with EC did not significantly reduce the risk of recurrence $(\mathrm{OR}=0.50$, 95\% CI $0.28-0.92, P<0.05)$ (Fig. $7)$. No heterogeneity was identified $\left(I^{2}=0 \%, P=0.98\right)$.

\section{Discussion}

This meta-analysis on the prevention of EC with metformin included 7 studies and a total of 5,293,039 participants. The pooled data suggested that the use of metformin could not substantially prevent the development of EC. When analyzing the subgroup of patients with diabetes, who were at a higher risk of EC, a significant protective effect of metformin against EC still could not be detected compared with patients with diabetes treated with other antidiabetic therapies. Differences in the duration of use and dose of metformin might have limited the statistical power of this study. The protective effects of metformin might be time and dose dependent [47]. However, most included studies failed to conduct dose-escalation analyses. Further, this meta-analysis also comprised 7 studies with a total of 3923 patients with EC who were treated with metformin. It was found that metformin could substantially improve the OS and reduce the risk of recurrence. The benefit for OS remained significant for the subgroup of patients with diabetes.

A previous meta-analysis based on 19 studies and illustrated effects of metformin on reversal of atypical 


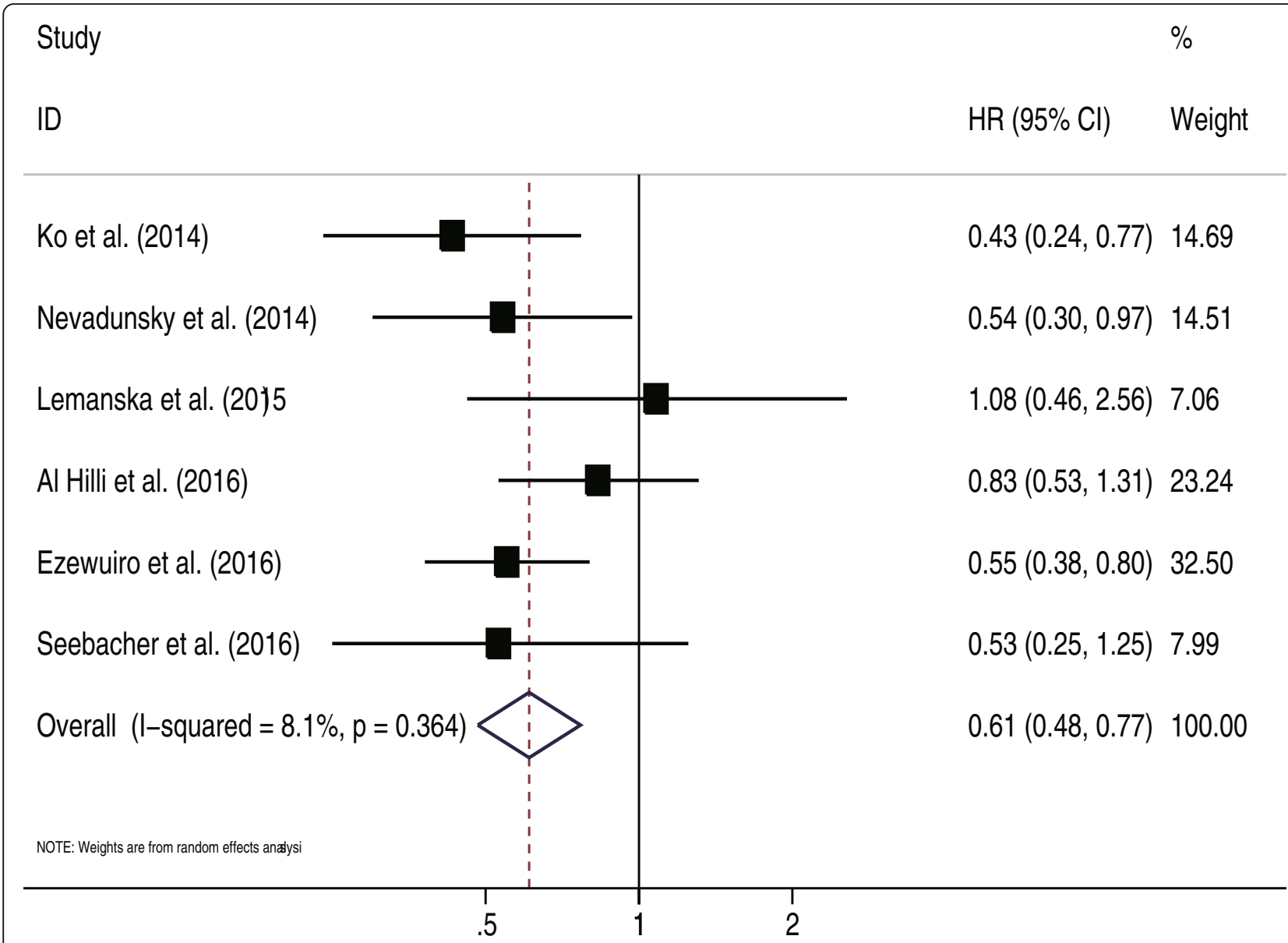

Fig. 5 Forest plot of the association between metformin use and overall survival of endometrial cancer

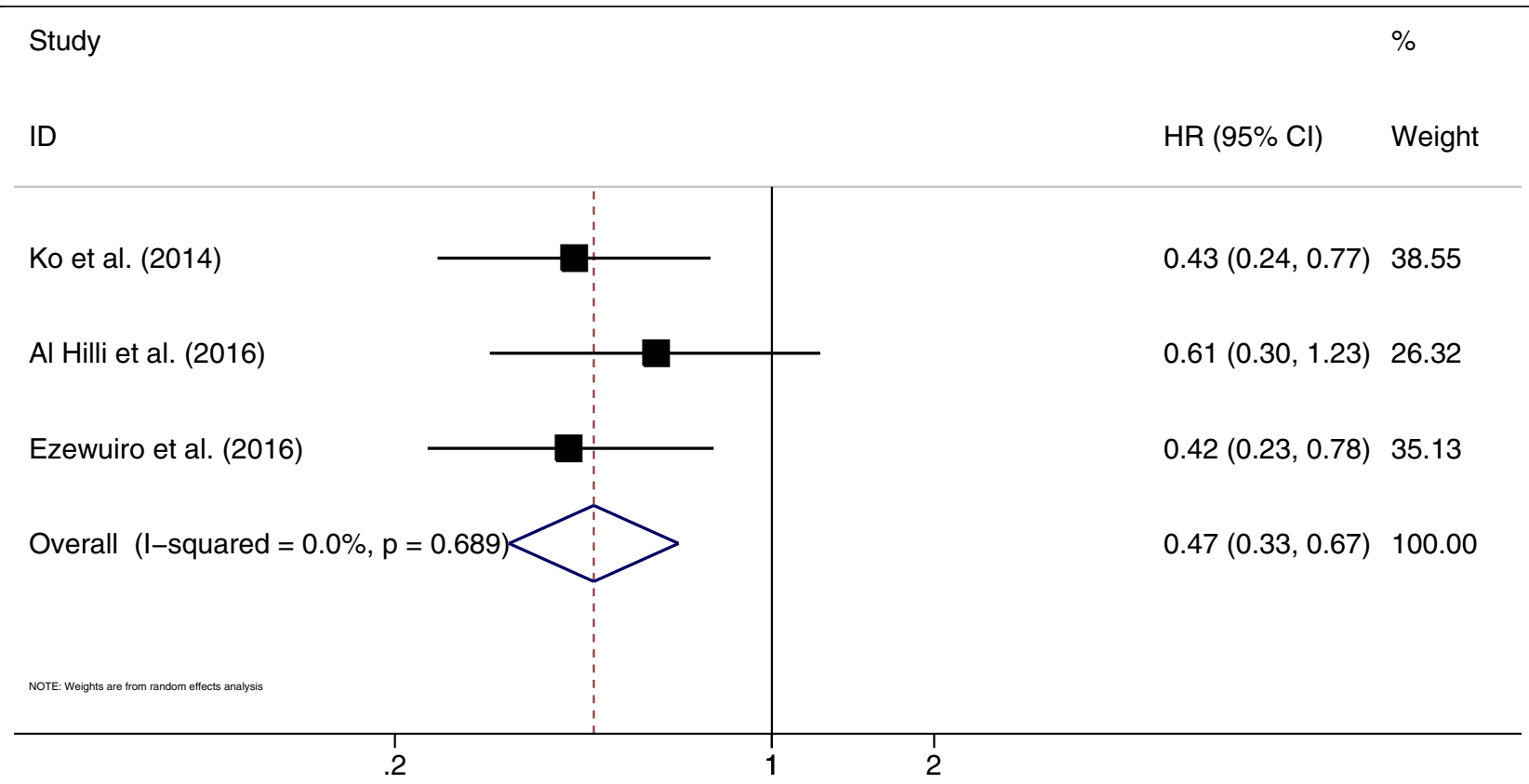

Fig. 6 Forest plot of the association between metformin use and overall survival of endometrial cancer among patients with diabetes 


\begin{tabular}{|c|c|c|}
\hline Study & & $\%$ \\
\hline ID & OR $(95 \% \mathrm{Cl})$ & Weight \\
\hline Seebacher et al. (2016) & $0.52(0.20,1.35)$ & 39.67 \\
\hline Hall et al. (2016) & $0.47(0.18,1.25)$ & 38.27 \\
\hline Ezewuiro et al. (2016) & $0.55(0.15,1.99)$ & 22.06 \\
\hline Overall $(I-$ squared $=0.0 \%, p=0.980)$ & $0.50(0.28,0.92)$ & 100.00 \\
\hline NOTE: Weights are from random effects analysis & & \\
\hline
\end{tabular}

Fig. 7 Forest plot of the association between metformin use and recurrence of endometrial cancer

endometrial hyperplasia, cellular proliferation biomarkers expression and overall survival. Further, they point out metformin could reverse atypical endometrial hyperplasia to normal endometrial histology, reduction of cell proliferation biomarkers, and improvement of OS. However, mostly investigated outcomes focused on precancerous indicators, while the risk of certain cancer was not evaluated [48]. The study conducted by Perez-Lopez et al. suggested metformin therapy was associated with a reduced risk of overall mortality in T2DM women with EC. Whereas this study focused on patients with T2DM and the preventive effect of metformin on EC risk was not illustrated [49]. Tang et al. conducted a meta-analysis based on 11 studies and indicated metformin therapy are significantly improvement EC risk and prognosis of EC. However, this study with incomplete electronic searches and the result of recurrence of EC were not calculated [50]. This novel meta-analysis of metformin use for preventing and treating EC analyzed both risk and survival scenarios. The most comprehensive up-to-date relevant studies were included. The sample sizes of most studies were sufficiently large, and the studies were of high quality. The inclusion of participants from all parts of the world meant that the present study results should be generalizable to the general population. Most studies sufficiently adjusted for various clinicopathological confounding factors. Moreover, the role of metformin was specifically assessed among patients with diabetes.

Abundant preclinical in vitro and in vivo studies have reported the anticancer effect of metformin on various malignancies. Nevertheless, the exact molecular mechanisms remain unknown. Metformin may inhibit cancer stem cell-like subpopulations in cases of intraepithelial neoplasia [51]. Metformin may also prevent the conversion of epithelial cells into mesenchymal cells [52]. Several studies have reported that metformin can reverse endometrial hyperplasia [53, 54]. Thus, metformin may have multiple functions mediated through direct and indirect mechanisms [51]. The indirect effect is insulin dependent. Metformin helps control the circulating glucose level and improve insulin sensitivity. The direct effect is insulin independent. Metformin exerts its effects on tumor cells primarily through the adenosine $5^{\prime}$-monophosphate-activated protein kinase and phosphoinositide 3-kinase/protein kinase $\mathrm{B} /$ mammalian target of rapamycin signaling pathways [55]. Notably, these molecular targets are similar to the targets of current drugs, such as sorafenib and everolimus. A phase I clinical trial of 21 cases, including 4 patients with advanced EC, showed that the combination of temsirolimus and metformin was a promising treatment [56]. Metformin is nontoxic and may be extremely useful for enhancing the treatment efficacy of the targeted drugs [51]. Since metformin has been used for more than 50 years, its safety profile has been well established. Although it can cause potentially dangerous toxicity from lactic acidosis, the risk is mainly confined to patients aged more than 80 years, patients with alcohol abuse, or those who have comorbidities of renal, hepatic, or cardiac insufficiency [57].

This meta-analysis had several limitations. It only identified a small number of studies exploring the role 
of metformin for prevention and treatment. Further, stratified results according to individuals characteristics were not reported. Therefore, a subgroup or metaregression analysis could not identify the sources of heterogeneity. Many of the included studies were retrospectively designed, which might have led to recall and selection bias, and those study are associated with low level of evidence. Furthermore, whether patients had taken different antidiabetic drugs before metformin administration could not be determined. Their glycemic control might also be inadequate. Moreover, this metaanalysis was based on observational data, which was associated with higher indication bias. Such as, more "healthier patients" always receive the best treatment. No randomized controlled trial has been conducted on patients with EC. Interestingly, a previous large randomized controlled trial that enrolled patients with gastrointestinal malignancies showed that metformin was helpful for the chemoprevention of colorectal cancer [58], but did not significantly improve the OS of patients with pancreatic cancer [59]. Most of the studies included in this meta-analysis did not report the effect of metformin dose or duration. Although most of the studies performed sufficient adjustment of variables, little information was available to evaluate the potential influence of other drugs such as aspirin or statins. Moreover, stratified analyses were not conducted based on study design and other patient characteristics, since a smaller number of cohorts were included. Therefore, this comprehensive meta-analysis just provided relative results on metformin use for EC prevention and treatment.

\section{Conclusions}

In conclusion, a preventive effect of metformin on the development of EC was not observed in this metaanalysis. However, metformin was beneficial in improving the OS and reducing the relapse risk for patients with EC. More prospective long-term studies should be conducted to verify the findings of the present study.

\section{Additional files}

Additional file 1: PRISMA Checklist. (DOC $65 \mathrm{~kb}$ )

Additional file 2: Newcastle-Ottawa scale for quality assessment of the included studies. (DOC $36 \mathrm{~kb}$ )

\section{Abbreviations \\ Cl: Confidence interval; EC: Endometrial cancer; HR: Hazard ratio; OR: Odds ratio; OS: Overall survival; RFS: Recurrence-free survival; RR: Relative risk}

\section{Funding}

National Natural Science Foundation of China (No. 31670844) and Program for Science and Technology Innovation Teams in Universities of Henan Province (No.17IRTSTHN021) provides financial supports in the study and the funders had no role in study design, data collection and analysis, decision to publish, or preparation of the manuscript.

\section{Availability of data and materials}

All data generated or analyzed during this study are included in this published article.

\section{Authors' contributions}

DC conceived and coordinated the study, designed, performed and analyzed the data, wrote the paper. JW, KW, MZ, CW, LL and RG carried out the data collection, data analysis, and revised the paper. All authors reviewed the results and approved the final version of the manuscript.

Ethics approval and consent to participate

All analyses were based on previous published studies, thus no ethical approval and patient consent are required.

Competing interests

The authors declare that they have no competing interests.

\section{Publisher's Note}

Springer Nature remains neutral with regard to jurisdictional claims in published maps and institutional affiliations.

Received: 2 August 2017 Accepted: 4 April 2018

Published online: 18 April 2018

\section{References}

1. Morice P, Leary A, Creutzberg C, Abu-Rustum N, Darai E. Endometrial cancer. Lancet. 2016;387:1094-108

2. Koh WJ, Greer BE, Abu-Rustum NR, Apte SM, Campos SM, Chan J, et al. Uterine neoplasms, version 2.2016. J Natl Compr Cancer Netw. 2016;12:248-80.

3. Tangjitgamol S, Anderson BO, See HT, Lertbutsayanukul C, Sirisabya N, Manchana T, et al. Management of endometrial cancer in Asia: consensus statement from the Asian oncology summit 2009. Lancet Oncol. 2009;10:1119-27.

4. Creasman WT, Odicino F, Maisonneuve P, Quinn MA, Beller U, Benedet JL, et al. Carcinoma of the corpus uteri. FIGO 26th annual report on the results of treatment in gynecological Cancer. Int J Gynaecol Obstet. 2006;95 Suppl 1:S105-43.

5. Chlebowski RT, Schottinger JE, Shi J, Chung J, Haque R. Aromatase inhibitors, tamoxifen, and endometrial cancer in breast cancer survivors. Cancer. 2015;121:2147-55.

6. Zhang D, Bai B, Xi Y, Zhao Y. Can aspirin reduce the risk of endometrial Cancer?: a systematic review and meta-analysis of observational studies. Int J Gynecol Cancer. 2016;26:1111-20.

7. Feng CH, Miller CM, Tenney ME, Lee NK, Yamada SD, Hasan Y. Statin use significantly improves overall survival in high-grade endometrial Cancer. Int J Gynecol Cancer. 2016;26:1642-9.

8. Chlebowski RT, Anderson GL, Sarto GE, Haque R, Runowicz CD, Aragaki AK, Thomson CA, Howard BV, Wactawski-Wende J, Chen C, Rohan TE, Simon MS, Reed SD, Manson JE. Continuous combined estrogen plus progestin and endometrial Cancer: the Women's Health Initiative randomized trial. J Natl Cancer Inst. 2015;108(3). https://doi.org/10.1093/jnci/djv350.

9. Nevadunsky NS, Van Arsdale A, Strickler HD, Moadel A, Kaur G, Frimer M, et al. Metformin use and endometrial cancer survival. Gynecol Oncol. 2014;132: 236-40.

10. Hall C, Stone RL, Gehlot A, Zorn KK, Burnett AF. Use of metformin in obese women with type I endometrial Cancer is associated with a reduced incidence of Cancer recurrence. Int J Gynecol Cancer. 2016;26:313-7.

11. Handelsman Y, Bloomgarden ZT, Grunberger G, Umpierrez G, Zimmerman RS, Bailey TS, et al. American association of clinical endocrinologists and american college of endocrinology - clinical practice guidelines for developing a diabetes mellitus comprehensive care plan - 2015. Endocr Pract. 2015;21 Suppl 1:1-87.

12. McCartney CR, Marshall JC. CLINICAL PRACTICE. Polycystic ovary syndrome. N Engl J Med. 2016;375:54-64.

13. Diabetes Prevention Program Research G. Within-trial cost-effectiveness of lifestyle intervention or metformin for the primary prevention of type 2 diabetes. Diabetes Care. 2003;26:2518-23.

14. Fontbonne A, Diouf I, Baccara-Dinet M, Eschwege E, Charles MA. Effects of 1year treatment with metformin on metabolic and cardiovascular risk factors in non-diabetic upper-body obese subjects with mild glucose anomalies: a posthoc analysis of the BIGPRO1 trial. Diabetes Metab. 2009;35:385-91.

15. Seifarth C, Schehler B, Schneider HJ. Effectiveness of metformin on weight loss in non-diabetic individuals with obesity. Exp Clin Endocrinol Diabetes. 2013;121:27-31. 
16. Rosato V, Zucchetto A, Bosetti C, Dal Maso L, Montella M, Pelucchi C, et al. Metabolic syndrome and endometrial cancer risk. Ann Oncol. 2011;22:884-9.

17. Friberg E, Orsini N, Mantzoros CS, Wolk A. Diabetes mellitus and risk of endometrial cancer: a meta-analysis. Diabetologia. 2007:50:1365-74.

18. Soliman PT, Wu D, Tortolero-Luna G, Schmeler KM, Slomovitz BM, Bray MS, et al. Association between adiponectin, insulin resistance, and endometrial cancer. Cancer. 2006;106:2376-81

19. Mu N, Zhu $Y$, Wang $Y$, Zhang $H$, Xue F. Insulin resistance: a significant risk factor of endometrial cancer. Gynecol Oncol. 2012;125:751-7.

20. Burzawa JK, Schmeler KM, Soliman PT, Meyer LA, Bevers MW, Pustilnik TL, et al. Prospective evaluation of insulin resistance among endometrial cancer patients. Am J Obstet Gynecol. 2011;204:355. e1-7

21. Giannarelli R, Aragona M, Coppelli A, Del Prato S. Reducing insulin resistance with metformin: the evidence today. Diabetes Metab. 2003;29:6S28-35.

22. Yanokura M, Irie H, Masuda K, Kobayashi Y, Tominaga E, Aoki D, et al. Modulation of the IGF system and proliferation in human endometrial stromal cells by metformin: a dose-dependent effect. ScientificWorldJournal. 2015;292:465-72.

23. Sivalingam VN, Kitson S, McVey R, Roberts C, Pemberton P, Gilmour K, et al. Measuring the biological effect of presurgical metformin treatment in endometrial cancer. Br J Cancer. 2016;114:281-9.

24. Schuler KM, Rambally BS, Difurio MJ, Sampey BP, Gehrig PA, Makowski L, et al. Antiproliferative and metabolic effects of metformin in a preoperative window clinical trial for endometrial cancer. Cancer Medicine. 2015;4:161-73.

25. Zhao H, Jiang Y, Liu Y, Yun C, Li L. Endogenous estrogen metabolites as biomarkers for endometrial cancer via a novel method of liquid chromatography-mass spectrometry with hollow fiber liquid-phase microextraction. Horm Metab Res. 2015:47:158-64.

26. Zhang Q, Celestino J, Schmandt R, McCampbell AS, Urbauer DL, Meyer LA, et al. Chemopreventive effects of metformin on obesity-associated endometrial proliferation. Am J Obstet Gynecol. 2013;209:24.e1-24.e12.

27. Moher D, Liberati A, Tetzlaff J, Altman DG, Group P. Preferred reporting items for systematic reviews and meta-analyses: the PRISMA statement. PLoS Med. 2009;6:e1000097.

28. Wells GA, Shea B, O'Connell D, Peterson J, Welch V, Losos M, et al. The Newcastle-Ottawa Scale (NOS) for assessing the quality of nonrandomised studies in meta-analyses. http://wwwohrica/programs/clinical_epidemiology/ oxfordasp.

29. Parmar MK, Torri V, Stewart L. Extracting summary statistics to perform meta-analyses of the published literature for survival endpoints. Stat Med. 1998;17:2815-34.

30. DerSimonian R, Laird N. Meta-analysis in clinical trials. Control Clin Trials. 1986;7:177-88.

31. Higgins JP, Thompson SG. Quantifying heterogeneity in a meta-analysis. Stat Med. 2002;21:1539-58.

32. Egger M, Davey Smith G, Schneider M, Minder C. Bias in meta-analysis detected by a simple, graphical test. BMJ. 1997;315:629-34.

33. Begg CB, Mazumdar M. Operating characteristics of a rank correlation test for publication bias. Biometrics. 1994;50:1088-101.

34. Becker C, Jick SS, Meier CR, Bodmer M. Metformin and the risk of endometrial cancer: a case-control analysis. Gynecol Oncol. 2013;129:565-9.

35. Luo J, Beresford S, Chen C, Chlebowski R, Garcia L, Kuller L, et al. Association between diabetes, diabetes treatment and risk of developing endometrial cancer. Br J Cancer. 2014;111:1432-9.

36. Ko EM, Sturmer T, Hong JL, Castillo WC, Bae-Jump V, Funk MJ. Metformin and the risk of endometrial cancer: a population-based cohort study. Gynecol Oncol. 2015;136:341-7.

37. Soffer D, Shi J, Chung J, Schottinger JE, Wallner LP, Chlebowski RT, et al. Metformin and breast and gynecological cancer risk among women with diabetes. BMJ Open Diabetes Res Care. 2015;3:e000049.

38. Tseng $\mathrm{CH}$. Metformin and endometrial cancer risk in Chinese women with type 2 diabetes mellitus in Taiwan. Gynecol Oncol. 2015;138:147-53.

39. Franchi M, Asciutto R, Nicotra F, Merlino L, La Vecchia C, Corrao G, et al. Metformin, other antidiabetic drugs, and endometrial cancer risk: a nested case-control study within Italian healthcare utilization databases. Eur J Cancer Prev. 2016;26:225-31.

40. Arima R, Marttila M, Hautakoski A, Arffman M, Sund R, llanne-Parikka P, et al. Antidiabetic medication, statins and the risk of endometrioid endometrial cancer in patients with type 2 diabetes. Gynecol Oncol. 2017;146:636-41.

41. Ko EM, Walter P, Jackson A, Clark L, Franasiak J, Bolac C, et al. Metformin is associated with improved survival in endometrial cancer. Gynecol Oncol. 2014; 132:438-42.
42. Lemanska A, Zaborowski M, Spaczynski M, Nowak-Markwitz E. Do endometrial cancer patients benefit from metformin intake? Ginekol Pol. 2015;86:419-23.

43. Al Hilli MM, Bakkum-Gamez JN, Mariani A, Cliby WA, Mc Gree ME, Weaver AL, et al. The effect of diabetes and metformin on clinical outcomes is negligible in risk-adjusted endometrial cancer cohorts. Gynecol Oncol. 2016;140:270-6.

44. Ezewuiro O, Grushko TA, Kocherginsky M, Habis M, Hurteau JA, Mills KA, et al. Association of Metformin use with outcomes in advanced endometrial Cancer treated with chemotherapy. PLoS One. 2016;11:e0147145.

45. Seebacher V, Bergmeister B, Grimm C, Koelbl H, Reinthaller A, Polterauer S The prognostic role of metformin in patients with endometrial cancer: a retrospective study. Eur J Obstet Gynecol Reprod Biol. 2016;203:291-6.

46. Duval S, Tweedie R. A nonparametric "trim and fill" method of accounting for publication Bias in meta-analysis. J Am Stat Assoc. 2000;95:89-98.

47. Chen HP, Shieh JJ, Chang CC, Chen TT, Lin JT, Wu MS, et al. Metformin decreases hepatocellular carcinoma risk in a dose-dependent manner: population-based and in vitro studies. Gut. 2013;62:606-15.

48. Meireles CG, Pereira SA, Valadares LP, Rêgo DF, Simeoni LA, Guerra ENS, et al. Effects of metformin on endometrial cancer: systematic review and meta-analysis. Gynecol Oncol. 2017;147:167-80.

49. Perez-Lopez FR, Pasupuleti V, Gianuzzi X, Palma-Ardiles G, HernandezFernandez W, Hernandez AV. Systematic review and meta-analysis of the effect of metformin treatment on overall mortality rates in women with endometrial cancer and type 2 diabetes mellitus. Maturitas. 2017;101:6-11.

50. Tang YL, Zhu LY, Li Y, Yu J, Wang J, Zeng XX, et al. Metformin use is associated with reduced incidence and improved survival of endometrial Cancer: a meta-analysis. Biomed Res Int. 2017;2017:5905384.

51. Del Barco S, Vazquez-Martin A, Cufi S, Oliveras-Ferraros C, Bosch-Barrera J, Joven J, et al. Metformin: multi-faceted protection against cancer. Oncotarget. 2011;2:896-917.

52. Cufi S, Vazquez-Martin A, Oliveras-Ferraros C, Martin-Castillo B, Joven J, Menendez JA. Metformin against TGFbeta-induced epithelial-tomesenchymal transition (EMT): from cancer stem cells to aging-associated fibrosis. Cell Cycle. 2010;9:4461-8.

53. Shen ZQ, Zhu HT, Lin JF. Reverse of progestin-resistant atypical endometrial hyperplasia by metformin and oral contraceptives. Obstet Gynecol. 2008; 112:465-7.

54. Shan W, Wang C, Zhang Z, Gu C, Ning C, Luo X, et al. Conservative therapy with metformin plus megestrol acetate for endometrial atypical hyperplasia. J Gynecol Oncol. 2014;25:214-20.

55. Martin-Castillo B, Vazquez-Martin A, Oliveras-Ferraros C, Menendez JA. Metformin and cancer: doses, mechanisms and the dandelion and hormetic phenomena. Cell Cycle. 2010;9:1057-64.

56. Khawaja MR, Nick AM, Madhusudanannair V, Fu S, Hong D, LM MQ, et al. Phase I dose escalation study of temsirolimus in combination with metformin in patients with advanced/refractory cancers. Cancer Chemother Pharmacol. 2016;77:973-7.

57. McCormack J, Johns K, Tildesley H. Metformin's contraindications should be contraindicated. CMAJ. 2005;173:502-4.

58. Higurashi T, Hosono K, Takahashi H, Komiya Y, Umezawa S, Sakai E, et al. Metformin for chemoprevention of metachronous colorectal adenoma or polyps in post-polypectomy patients without diabetes: a multicentre double-blind, placebo-controlled, randomised phase 3 trial. Lancet Oncol. 2016;17:475-83.

59. Kordes S, Pollak MN, Zwinderman AH, Mathot RA, Weterman MJ, Beeker A, et al. Metformin in patients with advanced pancreatic cancer: a double-blind, randomised, placebo-controlled phase 2 trial. Lancet Oncol. 2015;16:839-47. 